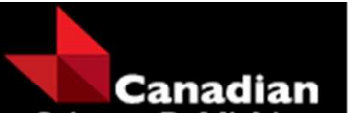

Science Publishing

Canadian Journal of Forest Research

Revue canadienne de recherche forestière

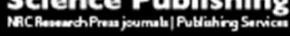

\title{
Experimental branch cooling increases foliar sugar and anthocyanin concentrations in sugar maple at the end of the growing season
}

\begin{tabular}{|c|c|}
\hline Journal: & Canadian Journal of Forest Research \\
\hline Manuscript ID & cjfr-2016-0534.R1 \\
\hline Manuscript Type: & Note \\
\hline Date Submitted by the Author: & 24-Jan-2017 \\
\hline Complete List of Authors: & $\begin{array}{l}\text { Schaberg, Paul; USDA Forest Service } \\
\text { Murakami, Paula; USDA Forest Service, Northern Research Station } \\
\text { Butnor, John; USDA-Forest Service, } \\
\text { Hawley, Gary; The Rubenstein School of }\end{array}$ \\
\hline Keyword: & fall leaf color, low temperature, sucrose, glucose, fructose \\
\hline
\end{tabular}

\section{SCHOLARONE ${ }^{\text {Tw }}$ \\ Manuscripts}


1 Experimental branch cooling increases foliar sugar and anthocyanin

2 concentrations in sugar maple at the end of the growing season

4 Paul G. Schaberg, Paula F. Murakami, John R. Butnor, Gary J. Hawley

5

6

7 P.G. Schaberg and P.F. Murakami, USDA Forest Service, Northern Research Station, 81

8 Carrigan Dr., Burlington, VT 05405, USA.

9

J.R. Butnor, USDA Forest Service, Southern Research Station, 81 Carrigan Dr., Burlington, VT

1105405, USA.

12

13 G.J. Hawley, University of Vermont, Rubenstein school of Environment and Natural Resources,

1481 Carrigan Dr., Burlington, VT 05405, USA.

15

16 Corresponding author: Paul G. Schaberg (e-mail: pschaberg@,fs.fed.us)

17

18 
20 Abstract: Autumnal leaf anthocyanin expression is enhanced following exposure to a variety of

21 environmental stresses and may be of adaptive benefit protecting leaves from those stresses,

22 thereby allowing for prolonged sugar and nutrient resorption. Past work has shown that

23 experimentally-induced sugar accumulations following branch girdling triggers anthocyanin

24 biosynthesis. We hypothesized that reduced phloem transport at low autumnal temperatures may

25 increase leaf sugar concentrations that stimulate anthocyanin production, resulting in enhanced

26 tree- and landscape-scale color change. We used refrigerant-filled tubing to cool individual

27 branches in a mature sugar maple (Acer saccharum Marsh) tree to test whether phloem cooling

28 would trigger foliar sugar accumulations and enhance anthocyanin biosynthesis. Cooling

29 increased foliar sucrose, glucose, and fructose concentrations 2- to nearly 10-fold (depending on

30 the specific sugar and sampling date) relative to controls, and increased anthocyanin

31 concentrations by approximately the same amount. Correlation analyses indicated a strong and

32 steady positive relationship between anthocyanin and sugar concentrations, which was consistent

33 with a mechanistic link between cooling-induced changes in these constituents. Tested here at

34 the branch-level, we propose that low temperature-induced reductions in phloem transport may

35 be responsible for increases in foliar sugars that trigger anthocyanin displays at grander scales.

37 Key words: fall leaf color, low temperature, sucrose, glucose, fructose, Acer saccharum 
42

\section{Introduction}

Anthocyanins are water-soluble pigments that reside within cell vacuoles in a wide variety of plants (Archetti et al. 2009). They are responsible for the red to purple colors observed in flowers, fruits, stems, and roots (e.g., Chalker-Scott 1999, Gould et al. 2010, Neufeld et al. 2011). Anthocyanins have been identified in both deciduous and evergreen species growing in a variety of ecosystems (e.g., Chalker-Scott 1999; Hughes et al. 2005; Archetti et al. 2009). Their broad existence across a wide range of sites has led to considerable debate regarding the specific roles anthocyanins play and the extent to which environmental triggers lead to their production. Research has linked the expression of anthocyanins to an assortment of environmental stresses including drought (Zhang et al. 2007), exposure to ozone and ultraviolet radiation (Alexieva et al. 2001, Gravano et al. 2004), wounding (Jeanette et al. 2000, Gould et al. 2002), bacterial and insect attacks (Gonzáles et al. 2002, Edwards et al. 2008), and nutrient deficiencies (Schaberg et al. 2003). One of the most notable displays of foliar anthocyanin production occurs in autumn within deciduous temperate forests and coincides with the onset of low temperatures (Feild et al. 2001, Schaberg et al. 2003). Likewise, observations of anthocyanin production have been observed in the young foliage of some temperate species when exposed to low temperatures in spring (Taulavuori et al. 2011). Among other temperature cues, freezing events have also been shown to trigger anthocyanin production (Hao and Arora 2009). Due to their consistent association with environmental stresses, anthocyanins are believed to impart a protective function within plant tissues. However, identifying a single specific protective role is currently the subject of much scientific debate, which has led to the development of numerous explanations regarding the ecological functions of anthocyanins (Archetti et al. 2009). Some of these include providing leaves with photoprotection (Neill and Gould 1999, Hughes et al. 2005), 
antioxidant capabilities (Gould et al. 2002, Neill and Gould 2003), prolonged periods of nutrient resorption (Hoch et al. 2003, Schaberg et al. 2008), serving as an "energy escape valve" (Hernández and Van Breusegem 2010) and providing signals to insects of a plant's defensive capabilities (Archetti et al. 2009).

In addition to anthocyanin production, a variety of environmental perturbations or stresses have also been shown to induce changes in sugar concentrations within plant tissues. For example, elevated carbon dioxide levels significantly increase soluble sugar concentrations in tree leaves (Liu et al. 2004) with a simultaneous up-regulation of the genes involved in anthocyanin expression (Tallis et al. 2010). Likewise, drought conditions (Gebre and Tschaplinski 2002) as well as pathogen infection (Bolouri-Moghaddam and Van den Ende 2012) can also result in an accumulation of foliar soluble sugars and anthocyanins. In particular, it is well established that low temperature exposure slows and can even halt phloem transport, thereby leading to foliar sugar buildups (e.g., Keskitalo et al. 2005, Thorpe et al. 2010). Mechanical disruption of the phloem can increase anthocyanin expression in a range of plant forms (e.g., Hughes et al. 2005), and previous research showed that girdling sugar maple (Acer saccharum Marsh.) branches just prior to the onset of autumnal low temperatures successfully trapped sugars within foliage and induced anthocyanin synthesis (Murakami et al. 2008). Foliar sugars and anthocyanin concentrations were up to five times greater in leaves of girdled branches than from control branches that were not girdled. Girdling stopped the flow of sugar transport, leading to an accumulation of sugars in leaves that triggered anthocyanin production as air temperatures decreased (Murakami et al. 2008). However, because both wounding (Jeanette et al. 2000, Gould et al. 2002) and low temperature exposure (Feild et al. 2001) are associated with anthocyanin production, autumnal girdling experiments cannot distinguish between these 
88 possible triggers. In particular, what remains uncertain is whether or not the influence of low

89 temperatures that slow phloem transport is analogous to the action of physical girdling in

90 increasing sugar accumulation and stimulating anthocyanin biosynthesis.

We hypothesized that low temperatures in autumn act as the environmental cue to slow

92 phloem transport, leading to a buildup of foliar sugars that trigger the biosynthesis of

93 anthocyanins in sugar maple leaves. Here we present the results of a unique experiment whereby

94 sugar maple branches were not wounded but experimentally cooled to reduce phloem transport

95 and then evaluated to determine if cooling increased both foliar sugar and anthocyanin

96 concentrations. Results of this experiment highlight the independent influence of low

97 temperature exposure from wound-induced anthocyanin production - providing a physiological

98 connection that is more directly relevant to tree-, stand- and landscape-level displays of foliar

99 reddening that accompany low air temperature exposure in autumn.

\section{Materials and methods}

\section{Branch cooling and collection of plant material}

A single open-grown sugar maple tree was chosen for this study at the USDA Forest Service

104 Northern Research Station in South Burlington, Vermont, USA (elevation $92 \mathrm{~m}$ a.s.1.) based on

105 its consistent display of yellow autumnal foliage from 1998-2008 (P. Schaberg unpublished

106 data). Using a tree that historically produced anthocyanins on a limited basis allowed for greater

107 resolution of treatment-induced changes. This tree was approximately $10 \mathrm{~m}$ tall, 33 years old,

108 and its leaves were green at the start of the experiment. Within this tree, two pairs of adjacent

109 south-facing branches were selected, and within each pair one branch was randomly assigned to 
110 be cooled and the other exposed to ambient temperatures (the control). Thermocouples were

111 inserted into pin-sized openings in the bark created with a stylus to the depth of the cambium to

112 continuously monitor phloem temperature of each branch. Cooling of phloem tissues was

113 achieved by circulating chilled liquid (ethylene glycol) from a cold-block system through plastic

114 tubing encircling branches, similar to the system used by Johnsen et al. (2007). Branches

115 assigned to the cooling treatment were wrapped with flexible plastic tubing to create a $30 \mathrm{~cm}$

116 long collar that was then covered with insulation. The average diameter of one cooled branch

117 was $19 \mathrm{~mm}$ with a total length of $2.33 \mathrm{~m}$, and the average diameter of the other cooled branch

118 was $18 \mathrm{~mm}$ with a total length of $2.37 \mathrm{~m}$. For these branches, a target temperature of $\sim 3^{\circ} \mathrm{C}$ was

119 maintained by a feedback loop that periodically pumped chilled ethylene glycol from a freezer to 120 branches.

One half of the leaves from treatment and control branches were randomly and equally

122 selected from along the length of each branch for harvest on September 26, 2008 (Julian Date

123 (JD) 270), and the remainder were collected one week later on October 3 (JD 277) for sugar and

124 pigment analyses. The total numbers of leaves collected per treatment were 23 for control

125 branches and 24 for cooled branches. Leaves were placed in plastic bags and transported to the 126 lab where they were immediately prepared for chemical analyses.

\section{Sugar analysis}

Five $0.5 \mathrm{~cm}$ leaf disks from four randomly chosen leaves were pooled for a total of 20

130 disks per sample for analysis. Leaf punches were submerged in $5 \mathrm{ml}$ of $80 \%$ ethanol and stored

131 at $-20^{\circ} \mathrm{C}$. Foliar glucose, fructose and sucrose concentrations were determined from a series of

132 ethanol extractions according to the methods of Hinesley et al. (1992). Chlorophyll was removed 
133 from soluble sugar extracts using a $\mathrm{C}_{18}$ Sep-Pak Plus Cartridge (Waters Corp., Milford, MA). In 134 preparation for sugar analysis, $200 \mu \mathrm{L}$ of the foliar sample extract was dried at $37^{\circ} \mathrm{C}$ in a limited 135 volume insert vial and then reconstituted in $200 \mu 10.1 \mathrm{mM}$ Ca EDTA. Each sample was filtered 136 through a $0.45 \mu \mathrm{m}$ syringe filter and then analyzed using high performance liquid 137 chromatography (Waters Corp., Milford, MA) equipped with a Sugar-Pak column at $90^{\circ} \mathrm{C}$ and 138 using $0.1 \mathrm{~mm} \mathrm{Ca}$ EDTA as the eluent at a flow rate of $0.6 \mathrm{ml} \mathrm{min}{ }^{-1}$. Waters Empower software 139 was used to quantify sugar concentrations which were expressed as $\mathrm{mg} \mathrm{cm}^{-2}$ leaf area.

\section{Foliar pigment analysis}

A separate group of 20 leaf disks comprised of five disks from each of the same four leaves used for sugar analysis was pooled per sample for pigment analysis. Leaf disks were

144 shredded using a razor blade and placed in $6 \mathrm{ml}$ of $80 \%$ acetone for chlorophyll extraction. 145 Another set of 20, shredded leaf disks was placed in $6 \mathrm{ml}$ of $3 \mathrm{M} \mathrm{HCl} / \mathrm{H}_{2} \mathrm{O} / \mathrm{MeOH}(1: 3: 16$, by 146 vol.) for extraction of anthocyanins using the methods of Gould et al. (2000). Absorbance of 147 pigments was measured using a DU 800 UV/VIS spectrophotometer (Beckman Coulter, 148 Fullerton, CA). Chlorophyll $a$ and $b$ concentrations were determined from the acetone extracts 149 using the equations provided by Lichtenthaler and Wellburn (1983) and expressed as $\mu \mathrm{gm}^{-2}$. 150 Anthocyanin absorbance was measured at $530 \mathrm{~nm}$ from the extracts of acidified methanol and 151 concentrations were determined after adjusting for the overlap in chlorophyll absorbance $\left(\mathrm{A}_{530^{-}}\right.$ $\left.1520.24 \mathrm{~A}_{653}\right)$ (Murray and Hackett 1991). 
$T$-tests were used to determine differences in soluble sugar and pigment concentrations

156

157

158

159

160

161

162

163

164

165

166

167

168

169

170

171

\section{Soluble sugar concentrations}

173

174

175

176

\section{Results}

\section{Branch cooling verification} comparisons $\left(13.51 \pm 0.82^{\circ} \mathrm{C}\right)($ Fig. 1$)$.

between the foliage of cooled and control branches. Although disks from individual leaves were

assessed, branch means were used for statistical analyses per date and for the two dates

combined. Differences were considered significant if $P<0.05$. Because variances were not equal in some instances, a Welch's test was used when necessary. Correlation analyses were conducted on pooled leaf samples and evaluated per treatment and date, and for combined dates to evaluate relationships among sugar and pigment concentrations.

Figure 1 depicts the success of cooling efforts. Control and treated branches had temperatures that were indistinguishable prior to the start of the cooling treatment (before September 12 - JD 256). However, they showed marked differences after treatment induction, with cooled branches maintaining relatively stable temperatures of $2.82 \pm 0.06{ }^{\circ} \mathrm{C}(\overline{\mathrm{X}} \pm \mathrm{SE})$ and control branches showing diurnal temperature fluctuations that were generally well above treated

After 14 days of branch cooling, foliage collected on September 26 contained significantly greater concentrations of sucrose, glucose and fructose $(P<0.0001)$ compared to foliage of control branches collected on the same day (Table 1). Indeed, cooling treatment resulted in foliar sugar concentrations that were approximately 2-9 times greater than their 
177 control counterparts. Although foliage collected in October generally contained lower

178 concentrations of soluble sugars than those measured in September, foliar sucrose concentrations

179 from cooled branches were two times higher than levels measured in foliage from control

180 branches $(P=0.0015)$. In contrast, fructose concentrations were marginally lower with cooling 181 treatment $(P=0.0933)$, and there were no differences in foliar glucose concentration. Foliar 182 glucose concentrations from control branches changed little from September to October, but 183 sucrose concentrations declined by more than half and fructose concentrations doubled $(P<$ 184 0.0001). Patterns of sugar accumulation with treatment for both dates combined mirrored those 185 for September, with 2-5 fold increases in sugar concentrations measured in leaves from the 186 cooling treatment relative to controls (Table 1).

\section{Chlorophyll and anthocyanin expression}

Synchronous with changes in foliar sugars, branch cooling significantly altered chlorophyll and anthocyanin concentrations, with significant treatment differences apparent on both collection dates (Table 2). In September, leaves of cooled branches had over three times less chlorophyll than leaves of control branches $(P<0.0001)$, though green coloration was still evident. By October, chlorophyll concentrations in foliage of cooled branches were nearly nine

194 times less than concentrations found in the foliage of control branches $(P<0.0001)$, and green 195 coloration appeared faded. As expected, green color and foliar chlorophyll content decreased 196 significantly $(P<0.0001)$ from September to October in control samples through natural 197 senescence. Anthocyanin concentration also exhibited significant treatment differences on both 198 collection dates (Table 2). Leaves harvested from cooled branches in September had distinct red 199 hues and contained anthocyanin levels that were over four times greater $(P<0.0001)$ than those 
200 found in foliage of control branches. Similarly, in October, anthocyanin concentration was 201 greatest $(P=0.0006)$ in leaves from cooled branches compared to those from control branches, 202 though red coloration appeared somewhat faded relative to September. Surprisingly, anthocyanin 203 concentration changed little from September to October in leaves of control branches $(P=$ 204 0.6118), but were significantly lower than concentrations in leaves of cooled branches $(P<$ 205 0.0001) with the greatest concentration occurring in September (Table 2). concentrations and anthocyanin expression during senescence-induced branch cooling. For

208 leaves from cooled branches, pooling data from both collection dates revealed that for all foliar 209 sugars (sucrose: $r=0.59 ; P=0.0028$, glucose: $r=0.78 ; P<0.0001$, fructose: $r=0.87 ; P<$ 2100.0001 , and total sugars: $r=0.78 ; P<0.0001$ ), concentrations were significantly and positively 211 correlated with anthocyanin levels. In leaves of control branches, only fructose $(r=0.41 ; P=$ $2120.0494)$ and total sugars $(r=0.41 ; P<0.049)$ were significantly correlated with anthocyanin 213 levels. On individual dates, only foliage harvested from cooled branches revealed significant 214 associations between sugar and anthocyanin concentrations; fructose $(r=0.68 ; P=0.0158)$ in 215 September, and glucose $(r=0.69 ; P=0.0181)$ and total sugars $(r=0.65 ; P=0.0307)$ in October.

\section{Discussion}

Overall, the hypothesis that branch cooling would slow phloem transport, lead to

219 buildups of foliar sugars and trigger anthocyanin biosynthesis in sugar maple leaves was

220 supported by our data. Branch cooling increased foliar concentrations of sucrose, glucose, and

221 fructose late in the growing season - a time when carbohydrate reserves generally move toward 
222 proximal winter storage sinks. These sugar increases were accompanied by two changes in leaf

223 pigmentation: increased anthocyanin and decreased chlorophyll concentrations. Synchronous

224 changes in foliar sugar and pigment concentrations with cooling suggest a mechanistic link

225 between temperature triggers and physiological response. This link was supported by

226 consistently strong correlations among the concentrations of various sugars and anthocyanins as

227 well as substantial experimental evidence from the literature.

Considerable evidence indicates that low temperatures slow phloem transport and

229 increase foliar sugar concentrations (e.g., Keskitalo et al. 2005, Thorpe et al. 2010). Other studies

230 have repeatedly linked sugar enhancement to anthocyanin production (Hiratsuka et al 2001, Hara

231 et al 2003), including among woody species under field conditions. For example, Ishikura (1976)

232 found an increase in total and reducing sugars followed by anthocyanin formation during

233 autumnal senescence of leaves in three genera (Acer, Rhus, and Euonymous), whereas Chang et

234 al. (1989) noted that increases in glucose and galactose were coupled with red color development

235 in senescing quaking aspen (Populus tremuloides) leaves. Schaberg et al. (2003) also showed a

236 significant and positive correlation between red coloration and sugar concentrations in senescing

237 sugar maple leaves.

Girdling experiments have provided evidence of a more causative association between

239 buildups of foliar sugars and anthocyanin expression. Jeanette et al. (2000) found that heat

240 girdling at the base of maize (Zea mays) leaves caused an increase in foliar sucrose

241 concentrations compared to controls, and that the anthocyanin content of girdled leaves then

242 increased considerably within 36 hours. The mechanistic connection between sugar and

243 anthocyanin concentrations has been bolstered by findings that sugars induce gene transcription

244 required for anthocyanin biosynthesis via the shikimic acid pathway (Hara et al. 2003). Indeed, 
245 the expression of a range of anthocyanin biosynthetic genes (e.g., CHS, CHI, C4H, F3H, DRF,

246 ANS, and UFGY) are enhanced by low temperature exposure (Zhang et al. 2011, 2012), with

247 sugar signaling initiating the biochemical cascades that trigger this (e.g., Vitrac et al. 2000, Hara

248 et al. 2003). In addition to their influence on anthocyanin biosynthesis, increases in sugar

249 concentrations may play a significant role in triggering leaf senescence, especially the loss of

250 chlorophyll in leaves (Wingler et al. 1998). We noted both anthocyanin increases and

251 chlorophyll loss with branch cooling and associated sugar increases.

Biochemical feedbacks between sugar and anthocyanin accumulations could be of

253 ecological benefit during senescence if they help coordinate changes in physiology that prolong

254 leaf longevity and extend the resorption of soluble carbohydrates and nutrients that could be of

255 competitive benefit during subsequent seasons. Anthocyanins may protect senescing leaves from

256 the negative effects of photoinhibition and scavenge reactive oxygen species produced via

257 photooxidation (Gould et al. 2002, Neill et al. 2002, Neill and Gould 2003). In addition, foliar

258 anthocyanin expression may allow for a prolonged period of nutrient resorption especially in

259 trees whose growing season may be inherently short due to a combination of environmental

260 stresses (Feild et al. 2001, Hoch et al. 2001, 2003). Hoch et al. (2003) proposed a "resorption

261 protection hypothesis" in which anthocyanins of senescing foliage shade the photosynthetic

262 system and prevent photoinhibition, allowing for a greater resorption of nutrients, particularly

263 nitrogen. This could be particularly pertinent to plants that seasonally experienced low

264 temperatures (Hoch et al. 2001). Similarly, Feild et al. (2001) emphasized the dual roles of

265 anthocyanins in senescing foliage as scavengers of reactive oxygen species as well as facilitators

266 of nutrient recovery in red osier dogwood (Cornus stolonifera). Schaberg et al. (2008) provided

267 the first anatomical evidence that anthocyanins may support nutrient resorption in senescing 
268 leaves. They found that red sugar maple leaves were more firmly attached and had less

269 abscission layer progression through petiolar vasculature compared to yellow leaves for which

270 the abscission layer was complete - indicating a termination of phloem transport. Indeed, red

271 leaves exhibited vascular connectivity more closely resembling green leaves (Schaberg et al.

272 2008). These results demonstrated a relationship between foliar coloration and abscission zone

273 formation, and suggest that, at least during senescence, red expression in sugar maple may allow

274 for an extended capacity for nutrient and sugar translocation compared to yellow leaf

275 counterparts.

Our findings highlight the influence of increased foliar sugar concentrations on the

277 autumnal expression of senescence and anthocyanin levels for cooled sugar maple shoots absent

278 the influence of wounding. The basic physiological connections associated with experimental

279 manipulation in our study are likely also pertinent to reports of red leaf coloration coincident

280 with native stresses such as mechanical injury (Jeanette et al. 2000) and certain types of insect

281 and fungal damage (Costa-Arbulú et al 2001, Rostás et al. 2002) that alter phloem transport and

282 sugar export. However, our low temperature treatment more specifically mimicked a more

283 pervasive, broad-scale trigger of anthocyanin production - reductions in autumnal air

284 temperature. Low temperatures during autumn lead to reductions in phloem transport (Keskitalo

285 et al. 2005). Here we show that experimental low temperature exposure also increased foliar

286 sugar concentrations and enhanced anthocyanin expression at the branch-level. We propose that

287 this same stimulus and response is pertinent to landscape-level foliar anthocyanin displays. An

288 association between low temperature exposure that triggers changes in carbohydrate relations

289 that then alter pigment physiology could provide a mechanistic explanation for patterns of fall

290 leaf coloration across time (e.g., between years of early versus late cold onset) and space (e.g., 
291 locations that experience cold early versus late in the season). Regardless of scale, we posit that

292 increased anthocyanin expression can then enhance leaf protection and extend opportunities to

293 retrieve and transport nutrients and soluble sugars to winter storage sites - a capacity that would

294 be of adaptive benefit to deciduous species in cold environments with short growing seasons.

296 Acknowledgements

We thank William Young for help with experimental setup and sample collections. We

298 also thank Kevin T. Smith, Abby van den Berg, Alexandra Kosiba, Rebecca Stern, Connie

299 Nozzolillo and two anonymous reviewers for their helpful suggestions regarding earlier drafts of

300 this manuscript. This study was funded in part by the USDA Forest Service Northern Research

301 Station, and the McIntire-Stennis Forest Research Program and National Research Initiative.

\section{References}

304 Alexieva, V., Sergiev, I., Mapelli, S., and Karanov, E. 2001. The effect of drought and ultraviolet 305 radiation on growth and stress markers in pea and wheat. Plant, Cell and Environ. 24: 1337$306 \quad 1344$.

307 Archetti, M., Döring, T., Hagen, S., Hughes, N., Leather, S., Lee, D., Lev-Yadun, S., Manetas, Y., 308 Ougham, H., Schaberg, P., and Thomas, H. 2009. Unravelling the evolution of autumn colours: 309 an interdisciplinary approach. Trends Ecol. Evolut. 24(3): 166-173.

310 Bolouri-Moghaddam, M., and Van den Ende, W. 2012. Sugars and plant innate immunity. J. Exp. 311 Bot. 63: 3989-98. 
312 Chalker-Scott, L. 1999. Environmental significance of anthocyanins in plant stress responses.

313 Photochem. Photobiol. 70:1-9.

314 Chang, K., Fechner, G., and Schroeder, H. 1989. Anthocyanins in autumn leaves of quaking 315 aspen in Colorado. For. Sci. 35: 229-236.

316 Costa-Arbulú, C., Gianoli, E., Gonzáles, W., and Niemeyer, H. 2001. Feeding by the aphid Sipha 317 flava produces a reddish spot on leaves of Sorghum halepense: an induced defense? J. Chem. 318 Ecol. 27: 273-283.

319 Edwards, W., Hall, J., Rowlan, A., Schneider-Barfield, T., Sun, T., Patil, M., Pierce, M., Fulcher, 320 G., Bell, A., and Essenberg, M. 2008. Light filtering by epidermal flavonoids during the 321 resistant response of cotton to Xanthomonas protects leaf tissue from light-dependent 322 phytoalexin toxicity. Phytochemistry 69: 2320-2328.

323 Feild, T., Lee, D., and Holbrook. N. 2001. Why leaves turn red in autumn. The role of 324 anthocyanins in senescing leaves of red-osier dogwood. Plant Physiol. 127: 566-574.

325 Gebre, G., and Tschaplinski, T. 2002. Solute accumulation of chestnut oak and dogwood leaves in 326 response to throughfall manipulation of an upland oak forest. Tree Physiol. 22: 251-260.

327 Gonzáles, W., Ramírez, C., Olea, N., and Niemeyer, H. 2002. Host plant changes produced by the 328 aphid Sipha flava: consequences for aphid feeding behaviour and growth. Entomologia 329 Experimentalis et Applicata 103: 107-113.

330 Gould, K., Dudle, D., and Neufeld, H. 2010. Why some stems are red: cauline anthocyanins 331 shield photosystem II against high light stress. J. Experiment. Bot. 61: 2707-2717.

332 Gould, K., Markham, K., Smith, R., and Goris, J. 2000. Functional role of anthocyanins in the 333 leaves of Quintinia serrata A. Cunn. J. Exper. Bot. 51: 1107-1115. 
334 Gould, K., McKelvie, J., and Markham, K. 2002. Do anthocyanins functions as antioxidants in 335 leaves? Imaging of $\mathrm{H}_{2} \mathrm{O}_{2}$ in red and green leaves after mechanical injury. Plant Cell Environ. 336 25: 1261-1269.

337 Gravano, E., Bussotti, F., Strasser, R., Schaub, M., Novak, K., Skelly, J., and Tani, C. 2004.

338 Ozone symptoms in leaves of woody plants in open-top chambers: ultrastructural and 339 physiological characteristics. Physiologia Plantarum 121: 620-633.

340 Hao, W., and Arora, R. 2009. Freezing tolerance and cold acclimation in guava (Psidium guajava 341 L.) HortSci. 44: 1258-1266.

342

343 344 345 346 347 348 349 350 351 352 353 354

Hara, M., Oki, K., Hoshino, K., and Kuboi, T. 2003. Enhancement of anthocyanin biosynthesis by sugar in radish (Raphanus sativus) hypocotyls. Plant Sci. 164: 259-265.

Hernández, I., and Van Breusegem, F. 2010. Opinion on the possible role of flavonoids as energy escape valves: Novel tools for nature's Swiss army knife. Plant Sci. 179: 297-301.

Hinesley, L., Pharr, L., Snelling, L., and Funderburk, S. 1992. Foliar raffinose and sucrose in four conifer species: relationship to seasonal temperature. J. Amer. Soc. Hort. Sci. 117: 852-855.

Hiratsuka, S., Onodera, H., Kawai, Y., Kubo, T., Itoh, H., and Wada, R. 2001. ABA and sugar effects on anthocyanin formation in grape berry cultured in vitro. Sci. Hortic. 90: 121-130.

Hoch, W., Singsaas, E., and McCown, B. 2003. Resorption protection. Anthocyanins facilitate nutrient recovery in autumn by shielding leaves from potentially damaging light levels. Plant Physiol. 133: 1296-1305.

Hoch, W., Zeldin, E., and McCown, B. 2001. Physiological significance of anthocyanins during autumnal leaf senescence. Tree Physiol. 21: 1-8. 
355 Hughes, N., Neufeld, H., and Burkey, K. 2005. Functional role of anthocyanins in high-light 356 winter leaves of the evergreen herb Galax urceolata. New Phytol. 168: 575-587.

357 Ishikura, N. 1976. Seasonal changes in contents of phenolic compounds and sugar in Rhus, 358 Euonymous and Acer leaves with special reference to anthocyanin formation in autumn. J. 359 Plant Res. 89: 251-257.

360 Jeanette, E., Reyss, A., Gregory, N., Gantet, P., and Prioul, J.-L. 2000. Carbohydrate metabolism 361 in a heat-girdled maize source leaf. Plant Cell Environ. 23: 61-69.

362 Johnsen, K., Maier, C., Sanchez, F., Anderson, P., Butnor, J., Waring, R., and Linder, S. 2007. 363 Physiological girdling of pine trees via phloem chilling: proof of concept. Plant Cell Environ. 364 30: $128-134$.

365 Keskitalo, J., Bergquist, G., Gardeström, P., and Jansson, S. 2005. A cellular timetable of autumn 366 senescence. Plant Physiol. 139: 1635-48.

367 Lichtenthaler, H., and Wellburn, A. 1983. Determinations of total carotenoids and chlorophylls $a$ 368 and $b$ of leaf extracts in different solvents. Biochem. Soc. Trans. 603: 591-592.

369 Liu, X., Kozovits, A., Grams, T., Blashke, H., Rennenberg, H., and Matyssek, R. 2004.

370 Competition modifies effects of enhanced ozone/carbon dioxide concentrations on

371 carbohydrate and biomass accumulation in juvenile Norway spruce and European beech. Tree

$372 \quad$ Physiol. 24: 1045-1055.

373 Murakami, P., Schaberg, P., and Shane, J. 2008. Stem girdling manipulates leaf sugar 374 concentrations and anthocyanin expression in sugar maple trees during autumn. Tree Physiol. 375 28: $1467-1473$. 
376

377

378

379

380

381

382

383

384

385

386

387

388

389

390

Murray, J., and Hackett, W. 1991. Dihydroflavonol reductase activity in relation to differential anthocyanin accumulation in juvenile and mature phase Hedera helix L. Plant Physiol. 97: 343351.

Neill, S., and Gould, K. 1999. Optical properties of leaves in relation to anthocyanin concentration and distribution. Can. J. Bot. 77: 1777-1782.

Neill, S., and Gould, K. 2003. Anthocyanin in leaves: light attenuators or antioxidants? Functional Plant Biol. 30: 865-873.

Neill, S., Gould, K., Kilmartin, P., Mitchell, K., and Markham, K. 2002. Antioxidant activities of red versus green leaves in Elatostema rugosum. Plant Cell Environ. 25: 539-547.

Neufeld, H., Poindexter, D., Murakami, P., and Schaberg, P. 2011. Observations on the relationship between above- and below-ground anthocyanin production in Galax urceolata (Poir) Brummitt growing in sun-exposed and shaded locations. Castanea. 76: 84-98.

Rostás, M., Bennett, R., and Hilker, M. 2002. Comparative physiological responses in Chinese cabbage induced by herbivory and fungal infection. J. Chem. Ecol. 28: 2449-2463.

Schaberg, P., Murakami, P., Turner, M., Heitz, H., and Hawley, G. 2008. Associations of red coloration with senescence of sugar maple leaves in autumn. Trees 22: 573-578.

Schaberg, P., van den Berg, A., Murakami, P., Shane, J., and Donnelly, J. 2003. Factors influencing red expression in autumn foliage of sugar maple trees. Tree Physiol. 23: 325-333.

Tallis, M., Lin, Y., Rogers, A., Zhang, J., Street, N., Miglietta, F., Karnosky, D., De Angelis, P., Calfapietra, C., and Taylor, G. 2010. The transcriptome of Populus in elevated $\mathrm{CO}_{2}$ reveals increased anthocyanin biosynthesis during delayed autumnal senescence. New Phytologist 186: 415-428. 
398 Taulavuori, K., Pihlajaniemi, H., Huttunen, S., and Taulavuori, E. 2011. Reddish spring colouring 399 of deciduous leaves: a sign of ecotype? Trees 25: 231-236.

400 Thorpe, M., Furch, A., Minchin, P., Föller, J., Van Bel, A., and Hafke, J. 2010. Rapid cooling $401 \quad$ triggers forisome dispersion just before phloem transport stops. Plant Cell Environ. 33: 259$402 \quad 271$.

403 Vitrac, X., Larronde, F., Krisa, S., Decendit, A., Deffieux, G., and Mérillon, J-M. 2000. Sugar 404 sensing and $\mathrm{Ca}^{2+}$-calmodulin requirement in Vitus vinifers cells producing anthocyanins. 405 Phytochem. 53: 659-665.

406 Wingler, A., von Schaewen, A., Leegood, R., Lea, P., and Quick, P. 1998. Regulation of leaf 407 senescence by cytokinins, sugars, and light. Effects on NADH-dependent hydroxypyruvate 408 reductase. Plant Physiol. 116: 329-335.

409 Zhang, B., Hu, Z., Zhang, Y., Li, Y., Zhou, S., and Chen, G. 2012. A putative functional MYB 410 transcription factor induced by low temperature regulates anthocyanin biosynthesis in purple 411 kale (Brassica Oleracea var acephala f. tricolor). Plant Cell Rep. 31: 281-289.

412 Zhang, J-L., Zhu, J-J., and Cao, K-F. 2007. Seasonal variation in photosynthesis in six woody 413 species with different leaf phenology in a valley savanna in southwestern China. Trees 21: 631414643.

415 Zhang, Y., Zheng, S., Liu, Z., Wang, L., and Bi, Y. 2011. Both HY5 and HYH are necessary 416 regulators for low temperature-induced anthocyanin accumulation in Arabidopsis seedlings. J. $417 \quad$ Plant Physiol. 168: 367-374. 
Table 1. Mean ( \pm SE) foliar sugar concentrations measured in control and cooled branches of a sugar maple tree on September 26 (Julian Date (JD) 270), October 3 (JD 277) and both dates combined. Differences were considered significantly different when $P \leq 0.05$. For all analyses, sample sizes were $\mathrm{n}=2$ branches per treatment.

\begin{tabular}{cccr}
$\begin{array}{c}\text { Sugar type per } \\
\text { collection date }\end{array}$ & \multicolumn{2}{c}{ Sugar concentration $\left(\mathrm{mg} \mathrm{cm}^{-2}\right)$} & \multirow{2}{*}{$P$} \\
\cline { 2 - 3 } & \multicolumn{2}{c}{ control } & \\
\hline $\begin{array}{c}\text { Sucrose } \\
\text { 26-Sep }\end{array}$ & $0.063 \pm 0.008$ & $0.139 \pm 0.012$ & $<0.0001$ \\
3-Oct & $0.016 \pm 0.003$ & $0.032 \pm 0.004$ & 0.0015 \\
combined dates & $0.039 \pm 0.006$ & $0.085 \pm 0.013$ & 0.0025 \\
& & & \\
Glucose & & & \\
26-Sep & $0.008 \pm 0.002$ & $0.079 \pm 0.006$ & $<0.0001$ \\
3-Oct & $0.010 \pm 0.004$ & $0.012 \pm 0.001$ & 0.6573 \\
combined dates & $0.009 \pm 0.002$ & $0.046 \pm 0.008$ & $<0.0001$ \\
& & & \\
Fructose & & & \\
26-Sep & $0.017 \pm 0.004$ & $0.145 \pm 0.010$ & $<0.0001$ \\
3-Oct & $0.037 \pm 0.009$ & $0.019 \pm 0.002$ & 0.0933 \\
combined dates & $0.027 \pm 0.006$ & $0.082 \pm 0.014$ & 0.0010 \\
\hline
\end{tabular}

Table 2. Mean ( \pm SE) foliar pigment concentrations measured in control and cooled branches of a sugar maple tree on September 26 (Julian Date (JD) 270, October 3 (JD 277) and both dates combined. Differences were considered significantly different when $P \leq 0.05$. For all analyses, sample sizes were $\mathrm{n}=2$ branches per treatment.

\begin{tabular}{crrr}
\hline $\begin{array}{l}\text { Pigment per } \\
\text { collection date }\end{array}$ & \multicolumn{3}{c}{$\begin{array}{c}\text { Pigment concentration }\left(\mathrm{mg} \mathrm{cm}^{-2}\right) \\
\text { Treatment }\end{array}$} \\
\cline { 1 - 3 } Chlorophyll & \multicolumn{2}{c}{$P$} & \\
\cline { 3 - 4 } 26-Sep & $20.615 \pm 1.122$ & $6.667 \pm 1.559$ & $<0.0001$ \\
3-Oct & $2.274 \pm 0.132$ & $0.254 \pm 0.054$ & $<0.0001$ \\
combined dates & $11.046 \pm 2.023$ & $3.461 \pm 1.014$ & 0.0021 \\
& & & \\
Anthocyanin & & & \\
26-Sep & $0.089 \pm 0.006$ & $0.372 \pm 0.037$ & $<0.0001$ \\
3-Oct & $0.093 \pm 0.006$ & $0.152 \pm 0.012$ & 0.0006 \\
combined dates & $0.091 \pm 0.004$ & $0.267 \pm 0.031$ & $<0.0001$ \\
& & & \\
\hline
\end{tabular}




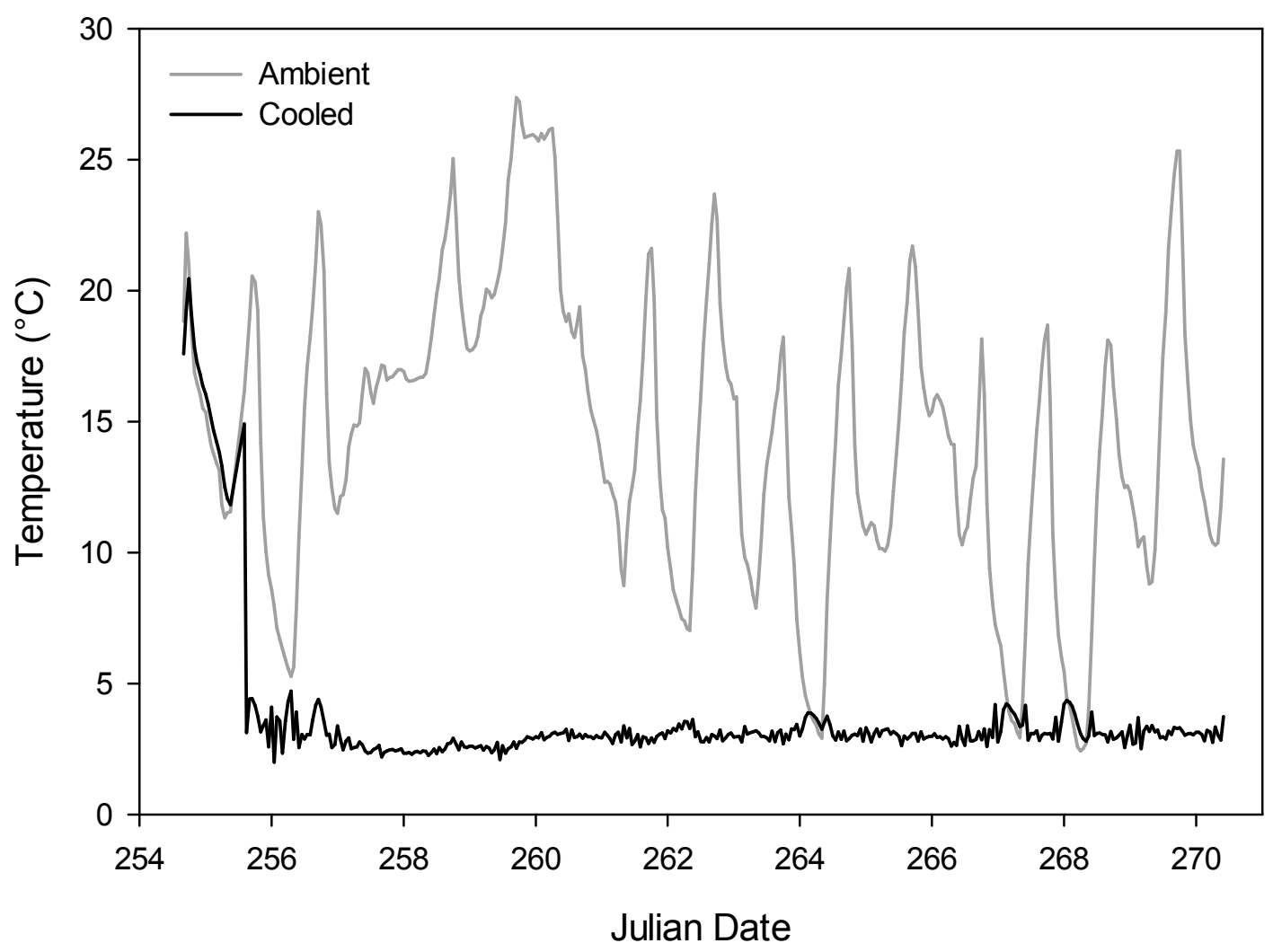

432

433 Fig. 1. Mean hourly temperatures of phloem tissues for control (ambient) and treated (cooled) 434 branches over the duration of the study. Cooling treatments began on day 256 (September 12) 435 2008. Julian Date is labeled at the midpoint of each day. 